\title{
Technological, Organizational and Environmental Framework for Digital Transformation in South African Financial Service Providers
}

\author{
Michael Makgale Modiba \\ North West University Business School \\ 11 Hoffman Street, 2531 \\ North West Province, South Africa
}

\author{
Ray M Kekwaletswe \\ North West University Business School \\ 11 Hoffman Street, 2531 \\ North West Province, South Africa
}

\begin{abstract}
This paper addresses technological, organizational and environmental contexts as experienced within South African Financial Service Providers, with respect to digital transformation. Although digital transformation is well studied, the research problem is that literature inadequately addresses how these three contexts manifest and play a role as financial service providers transform to digital business. Informed by interpretivist philosophy stance and case study strategy, this paper shows how digital transformation is enabled or inhibited by contextual influences. The paper argues that digital transformation ought to manifest cognizant of the context in which the financial service provider finds itself. To this point, the paper conceptualises a framework that may help in the digital business transformation.
\end{abstract}

Keywords:- Digital Business, Transformation, Financial Service Provider, South Africa, TOE Contexts.

\section{INTRODUCTION}

This paper is about the what and the how of digital transformation, notably in the context of South African financial service providers. In this era, digital transformation is considered imperative if Financial Service Providers (FSPs) are to be responsive to customer and stakeholder needs, through digital business. The paper addresses a pertinent information systems key issue, especially since digital transformation is in its infancy stage in South Africa. Notwithstanding this, there is still no outright theoretical and practical framework sensitive to South African Financial Service Provider contexts. This paper posits that, the technological, organizational and environmental contexts are key to organizational digital transformation journey. The paper acknowledges that the digital transformation is not a well understood phenomenon in its context.

Digitization, products and services and business models (Osterwalder and Pigneur, 2010) concentrate on processes and function. Digitization also means in this sense, the relation between people and things like material and property. The focus of processes and research has been on digitization throughout decades. In the past, the IT department has been mainly the only one focusing on the digitization, but now all other business units are affected. The IT organization has moved from administrative service to commercial operations (Gimpel and Roglinger, 2015). Today, businesses go far beyond merely automating internal processes. They also overhaul entire company processes to meet the increased customer demand questioning and replacing anything related to an existing mechanism with state-of-the-art digital technology (Markovitch and Willmott, 2014).

The digitization of products and services does not only include the modern, interactive or digital approach; the digitalization of products and services is also physical (Berman and Bell, 2011). In the late 1990s, digital engines pushed all industries into the digital end of the old physical - old continuum in a few fields, such as music, entertainment and telecommunications. Due to the advent of smarter and cheaper, smaller sensors (i.e. transmitters, RFID tags), almost every physical product, workpiece, asset, pallet, container, vehicle for transport, clothing, accessories and even the human body can now be fitted with electronic tags that allow the company to monitor the physical object in motion, for example. In addition to smart products, a convergence of physical products with digital technology allows companies, including new solutions which extend existing service offers, digital services which strengthen physical products or hybrid product service packages to provide smart solutions that rely on or require digital technology (Gimpel and Rogeliers, 2015)

\section{A. Understanding Digital Transformation}

Digital transformation in companies include changing products and business processes. In order to handle their complicated transitions, organizations must build organizational frameworks (Matt et al. 2015). In addition, the rapid and fundamentally changing of the emerging technology, which impacts on their lives and economies, affects people through the emerging transition (Ebert and Duarte, 2016). Various businesses and public entities are under pressure to become digital before it is too late, as innovations are being built to survive and retain their competitive advantage (Westerman et al., 2011). 
The below table 1 outlines various author's digital transformation definitions.

\begin{tabular}{|c|c|}
\hline Source & Definition \\
\hline $\begin{array}{l}\text { European Commission } \\
\text { (2019) }\end{array}$ & $\begin{array}{c}\text { "Digital transformation is characterized by a fusion of advanced technologies } \\
\text { and the integration of physical and digital systems, the predominance of } \\
\text { innovative business models and new processes, and the creation of smart } \\
\text { products and services." }\end{array}$ \\
\hline OECD (2018) & $\begin{array}{c}\text { "Digital transformation refers to the economic and societal effects of } \\
\text { digitization and digitalization. Digitization is the conversion of analogue data } \\
\text { and processes into a machine-readable format. Digitalization is the use of } \\
\text { digital technologies and data as well as their interconnection which results in } \\
\text { new or changes to existing activities." }\end{array}$ \\
\hline $\begin{array}{l}\text { Ismail, Khater, and Zaki } \\
\text { (2017) }\end{array}$ & $\begin{array}{l}\text { [Digital transformation is a] "process through which companies converge } \\
\text { multiple new digital technologies, enhanced with ubiquitous connectivity, with } \\
\text { the intention of reaching superior performance and sustained competitive } \\
\text { advantage, by transforming multiple business dimensions, including the } \\
\text { business model, the customer experience (comprising digitally enabled } \\
\text { products and services) and operations (comprising processes and decision- } \\
\text { making), and simultaneously impacting people (including skills talent and } \\
\text { culture) and networks (including the entire value system)." }\end{array}$ \\
\hline Schwertner (2017) & $\begin{array}{c}\text { "the application of technology to build new business models, processes, } \\
\text { software and systems that result in more profitable revenue, greater } \\
\text { competitive advantage, and higher efficiency." }\end{array}$ \\
\hline Deloitte (2018) & $\begin{array}{c}\text { "Digital transformation is the use of technology to radically improve the } \\
\text { performance or reach of an organization. In a digitally transformed business, } \\
\text { digital technologies enable improved processes, engaged talent, and new } \\
\text { business models." }\end{array}$ \\
\hline Bloomberg (2018) & $\begin{array}{l}\text { "Digital transformation requires the organization to deal better with change } \\
\text { overall, essentially making change a core competency as the enterprise } \\
\text { becomes customer-driven end-to-end. Such agility will facilitate ongoing } \\
\text { digitalization initiatives but should not be confused with them." }\end{array}$ \\
\hline
\end{tabular}

Table 1:- Definitions of the term "digital transformation"

As a contribution to existing digital transformation body of knowledge, we simply define digital transformation as re-organization of business process, business models and procedures through the eyes of customers with the aid of emerging advanced technologies. Transformation is about change, re-looking at how business activities are carried out and how they can be improved to deliver better results for the business and improved customer service.

\section{B. South African Context}

This paper vigorously acknowledges that South Africa is unique and globally categorized as a developing country. To this point, what works in other countries, notably i.e. developed countries, does not necessarily work as expected in South Africa. For example, a number of South African businesses, such as FSP's, service a variety of customers who live in rural, urban and suburb areas. However, rural areas customers have limited technological accessibility as compare to urban and suburbs customers. Consequently, access to FSP services is enhanced through digital technology. Therefore, there have been many developments in establishing digital transformation over past two decades in the "Western World". Within developing countries particularity South Africa, this has been even more of a challenge as these countries have had compounding issues in establishing digital transformation as a result of steady economic growth, technology, infrastructure, language, cultural diversity and political backdrops, for example politics play a role when doing business for either private or public sector. These additional complexities have stifled digital transformation in broader and more complex manner. South African has about ten spoken languages, with the majority of communities able to speak "isiZulu" language in addition to English (see figure 1 below). FSPs are compelled to ensure that their manuals, application forms, cash automated machines (ATM's) and call centres accommodate a variety of South African languages, although English language remains a business medium of communication.

The unique South African contexts poses challenges which require tailor-made solutions. 


\begin{tabular}{|c|c|c|c|}
\hline \multicolumn{2}{|c|}{ Language name } & \multicolumn{2}{|c|}{ Speakers as a 1st language } \\
\hline English & Endonym & Count $\triangleq$ & Of population $\hat{\imath}$ \\
\hline Zulu & isiZulu & $11,587,374$ & $22.7 \%$ \\
\hline Xhosa & isiXhosa & $8,154,258$ & $16.0 \%$ \\
\hline Afrikaans & Afrikaans & $6,855,082$ & $13.5 \%$ \\
\hline English & English & $4,892,623$ & $9.6 \%$ \\
\hline Northern Sotho & Sesotho sa Leboa & $4,618,576$ & $9.1 \%$ \\
\hline Tswana & Setswana & $4,067,248$ & $8.0 \%$ \\
\hline Sesotho & Sesotho & $3,849,563$ & $7.6 \%$ \\
\hline Tsonga & Xitsonga & $2,277,148$ & $4.5 \%$ \\
\hline Swati & siSwati & $1,297,046$ & $2.5 \%$ \\
\hline Venda & Tshivenda & $1,209,388$ & $2.4 \%$ \\
\hline Ndebele & isiNdebele & $1,090,223$ & $2.1 \%$ \\
\hline SA Sign Language & & 234,655 & $0.5 \%$ \\
\hline Other languages & & 828,258 & $1.6 \%$ \\
\hline To & tal & $50,961,443$ & $100.0 \%$ \\
\hline
\end{tabular}

Fig 1:- Distribution of languages Spoken in South Africa (Census 2011: Census in brief, Statistics South Africa, 2012. pp. 23-25)

\section{South African Financial Service Providers}

South African Investor's Handbook (2014/15) outlines business industry sectors in the country. The following is a description of the financial services industry. The South African banking industry is primarily governed by the Banks Act 94 of 1990, which seeks; "To provide for the regulation and supervision of the business of public companies taking deposits from the public; and to provide for matters connected therewith."

Banking systems play a pivotal role in modern economies around the world, and this is the same for South Africa (SA). The SA banking industry is made up of 17 registered banks, 15 local branches of foreign banks, 3 mutual banks, 2 cooperative banks and 36 representative offices. The industry controls R4 877 billion (ZAR) in total assets. Of which, the five dominant banks accounts for the $90.7 \%$ (which has seen an increase from 2015 to 2016) of the total assets in the industry, international banks $5.8 \%$ and $3.5 \%$ is spread across the remaining players. In 2016 the South African Reserve Banks (SARB) has issued three new entrants authorisation to trade, namely, Tyme Capital (Pty) Limited, Discovery Limited and Postbank Limited (SARB, 2016).

The financial services industry in South Africa boasts dozens of national and foreign organizations offering a complete variety of services including commercial, retail and merchant banking, mortgage loans, insurance and investment. South Africa's banking system, comprising a
Reserve Bank, some big financially powerful banks or investing organizations, and a number of smaller banks, is well developed and efficiently controlled. Competition is in investment and commercial banking. The banking sector of the country compares favorably with that of the industrialized countries. Throughout the previous decade, South Africa's financial service industry has been operated by numerous international banks and investment organizations.

South African financial services sector includes a wide variety of financial management companies such as banks, investment companies, insurance companies, and real estate firms. Economic services offered by the South African financial services providers are listed below as follows:

$>$ Credit unions

$>$ Banks

$>$ Credit-card firms

$>$ Insurance companies

$>$ Accounting companies

$>$ Consumer lending companies

$>$ Securities brokerages

$>$ Investment funds"

$>$ Corporate managers

$>$ Government funded enterprises

The next section discusses existing digital transformation frameworks and digital transformation "hot topics" that are relevant to this paper. 


\section{SURVEY OF SCHOLARSHIP}

\section{A. Digital Innovation Strategy Framework}

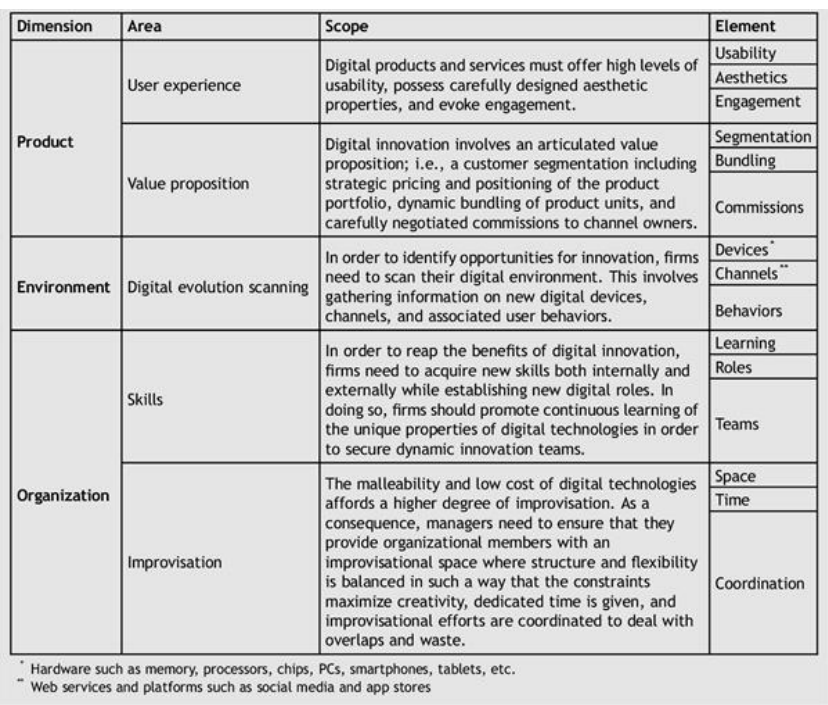

Fig 2:- Digital Innovation Strategy Framework Nylén, D. and J. J. B. H. Holmström (2015).

Nylen and Holmstrom (2015) proposed a Digital Innovation Strategy Framework for diagnosing and improving digital products and service innovation. However, the framework has its main weakness in that it focuses solely on numerical products and services. Traditional companies that can digitalize certain aspects of their operations and customer participation are limited to the context of the platform by offering products and services that cannot be completely digitalized or delivered digitally.

Nonetheless, the framework offers a useful tool which helps organizations to diagnose digital products and services in their path to improved digital products and services. Three broad categories are included: ' Products ' cover user experience and value proposition; ' Environment ' - covering scanning for digital evolution; and finally, Organisation, ' which covers skills and improvisation.

\section{B. Digital Transformation Framework}

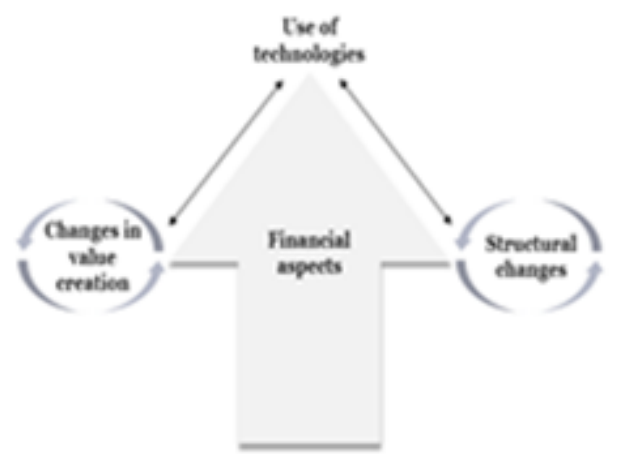

Fig 3:- Digital Transformation Framework (Matt et al., (2015).
The Digital Transformation Framework is another framework that aims at understanding digital transformation processes in an organization, the framework is developed by Matt et al., (2015). The framework has been premised on the idea that the organization's digital transformation would serve as a central concept incorporating all the organizational planning, priority and digitalisation implementation.

According to Ibid et al., (2015), "digital transformation strategies should include four key areas: technology use, changes in value creation, structured modifications and financial considerations". At the very heart of this paradigm is the financial aspect, which is the primary driver and motivator, a novel method for providing a framework for understanding the complexities of a business enterprise's digital transformation, in that the focus of a company is on sustainable growth and benefit over the long term.

The framework provides a fundamental academic basis for understanding digitization, through the description of four important building blocks for digital transformation. Ibid et al., (2015) suggest future research to define and concretize common elements that can be connected to four dimensions that form the foundation of the framework. It should be noted that, while this structure has been formulated and developed within the universities, it must still be checked or validated as a robust framework that can be applied to Digitisation understanding. Therefore, the conceptual stage of development remains.

\section{Digitization: drivers, objects and impacts}

The fourth industrial revolution is underway. Parker and Thomson (2016) suggest that 13 indicators that an industrial revolution could be around the corner were found in the World Economic Forum's Global Agenda Council on the Future of Technology and Society. The indicators are as follows:

> Implantable and wearable technologies

$>$ Our digital presence

$>$ Vision as a new interface

$>$ Ubiquitous computing

$>$ A supercomputer in your pocket

$>$ Storage for and for everything

$>$ The internet of and for things

$>$ Smart cities and smarter homes

$>$ Big data for big insights

$>$ Robots, decision-making and the world of work

$>$ The rise of digital currencies

$>$ Sharing economics

$>3 \mathrm{D}$ printing

Regardless of whether such megatrends constitute a fourth (or even a third) industrial revolution, and when that transition is taking place, one thing becomes clear: the process of switching from analog to digital (Gartner n.d.a), 'digitization,' becomes not just a concept. This already has a tremendous influence on businesses, the economy and individuals. In reality, 'the effects of a growing digitized world now touch every corner of our lives' (Friedrich et al., 2011). 


\section{Objects of Digitization}

Digitization, products and services and models of industry (Osterwalder and Pinteur, 2010) are the topics of processes and research. Digitization often implies interactions between people and things such as content and property. The center of processes and work has been digitization for decades. The IT Department was once mainly digitized for data collection and retrieval, but it is now affecting all of the departments. It has moved from administrative to commercial operations (Gimpel and Roglinger, 2015). Today, businesses go far further than merely automating internal processes. They also overhaul whole company processes to meet the growing demand of customers questioning and replacing anything related to an existing mechanism with state-of-the-art digital technology (Markovitch and Willmott, 2014).

The digitization of products and services does not only include the modern, interactive or digital approach; the digitalization of products and services is also physical (Berman and Bell, 2011). In the late 1990s, digital engines pushed all industries into the digital end of the old physical - old continuum in a few fields, such as music, entertainment and Telecommunications. Due to the advent of smarter and cheaper, smaller sensors (i.e. transmitters, RFID tags), almost every physical product, workpiece, asset, pallet, container, vehicle for transport, clothing, accessories and even the human body can now be fitted with electronic tags that allow the company to monitor the physical object in motion, for example.

In addition to smart products, a convergence of physical products with digital technology allows companies, including new solutions which extend existing service offers, digital services which strengthen physical products or hybrid product service packages to provide smart solutions that rely on or require digital technology (Gimpel and Rogeliers, 2015).The cloud-based integrated SAP Asset Intelligence Network (AIN) allows OEM operators and service providers to use upload, capture, control, track, and manage common assets and allows members to benefit from IoT. Operators have access from manufacturers who upload their goods to their digital twin to existing repair procedures, manuals and more. According to the International Digital Center (IDC), in its products / services, supply networks, distribution channels and operating systems by 2018 (Anderson et al., 2015) 75 percent of Globally 2000 would have developed robust economic knowledge models and digital twins.

The other topic of digitization is business models. The above examples demonstrate that the distinction between the digitization of products, services and business models is broken. That's because the value proposition is a pillar of a business model in a bundle of products and services that creates value for one specific customer segment (Osterwalder and Pigneur, 2010). Another concept is the marketplace market where "other consumers outside of the company generate value - many of whom encourage the company to create entirely new digital models" (Daugherty et al., 2015). Subscription to application programming interfaces (APIs), the secret sauce of the digital economy, companies can quickly add new business functionality to their current application.

Platform ecosystems are of strategic significance in all types of companies: asset heavy enterprises such as GE and Philips, asset light enterprises such as Google or Uber, and combined with successful platform ecosystems and assetdriven enterprises such as Apple and Amazon (Ibid et al., 2015). These brief explanations of digitization products demonstrate that digital innovations have greatly expanded business opportunities in all markets and industries to reimagine their key levers, from processes and functions to entire business models through products and services. Digitization now changes both 'how' and 'what' and there is no limit: it can digitize everything that can be digitized (Negroponte, 1995) and link everything that can be connected (Morgan, 2014). The continued rise in the width and depth of the digitization is the second explanation why the new optical wave differs from the previous one.

\section{E. Impacts of Digitization}

Digitization's influence includes broad and varied economic and social effects, unparalleled opportunities and major business challenges. Digitization has major impacts on the economy and society as a whole in a broad variety of ways including growth, market behavior, industrial environments, value chains structure, investments, efficiency, demand, jobs, skills, work conditions and rules on competition and market conduct (Hirt and Willmott, 2014; Schwab, 2016a).

The growth of the digital economy is expected to constitute 25 per cent of the global economy by 2020, from 15 per cent in 2005 (Daugherty et al., 2016), according to the digital economic value index of Accenture. In addition to allowing rivals to emerge from unexpected places and paving the way for rapidly emerging new business models, the lowering of entry barriers by digitization also leads to the disaggregation of value chains, long-established boundaries between tumbling sectors and the development of entirely new industries (Hirt and Willmott, 2014). While various geographies, markets, and businesses are digitized at different rates, digitization has an effect on geography, industry, and sector (Opitz et al., 2015; Berman and Bell, 2011; Friedrich et al., 2011; Daugherty et al., 2016). Company undergoes a digital transformation, causing some crisis, some as part of its core strategy and some as part of a more controlled process of transition (Bonnet and Nandan, 2011).

Today's emerging forces bring enormous opportunities and challenges to all companies, or both. As a result, digital technologies are increasingly determining whether a business is creating or losing value (Hirt and Willmott, 2014). Regarding the digitization advantages, few companies need to be sold (Desmet et al., 2015), as each company knows its disruptive potential (Daugherty et al., 2016). Taking advantage of this and other opportunities can help key performance metrics such as cost, sales, income, capital gain, satisfaction of customers and 
employees, and business evaluation. Digitization, on the other hand, poses big obstacles for businesses. Many of these issues can be subordinated to the overall question of how to effectively adapt to digitization or how to prevent disruption in terms of the largest threat to digitization.

Digitization will influence all variables and alter the entire business environment. Therefore, businesses need to address all the consequences of a digital transformation, reimagine all aspects of their business and create coherent end-to-end strategies and adjust accordingly (Ernst \& Young, 2011). Organizations that fail to digitize will certainly lose their interest and fail. This risk especially concerns well-established companies that are not clearly organized around or operating in the digital economy but whose future depends heavily on successful digital innovation and transformation (Gimpel and Roglinger, 2015).

Another challenge for businesses in the digital world is the constant threat of cyber-attacks (Raconteur, 2016b). Digitization is therefore a self-perpetuating process and enormous are the impacts of digitization on the economy as a whole, massive opportunities and big challenges for businesses. The answers to the question why the current wave of digitization varies from previous changes have to do with its historical size, speed, and scope (Schwab, 2016a). The 4th Industrial Revolution is marked by inevitability, irreversibility, difficulty in its execution and ubiquity.

\section{F. Digitalization: digital innovation and transformation}

"The use of emerging technology to shift a market trend and provide income and new value-generating opportunities can be defined as a transformation phase to an emerging sector" (Gartner n.d.b). A digital enterprise can be defined as "modern business concepts through the convergence of digital and physical environments" (Lopez, 2014) or as a company where digital technology focuses on value generation. In this context, digitalization is often referred to as 'digital transformation,' the terminology that we are dealing with falls short of the mark because it reflects only indirectly the main part of innovation; innovation and transformation are both critical for generating value in the digital economy. Digitalization is no longer an option but a requirement, considering the characteristics and impacts of digitization (Dreischmeier et al., 2015); digitalization or drowning is the mantra for all businesses in all industries and regions.

\section{THEORETICAL FRAMEWORK}

\section{A. Technology Organizational and Environmental Framework (TOE)}

TOE is the commonly used paradigm in the field of qualitative analysis within information systems. Depietro et al. (1990) states that three principles, the "technical, organizational and environmental sense, govern a company's process and the implementation of technological developments." The three principles influence how a company views, seeks and adopts the need of emerging technology. Furthermore, the authors suggest that technology is usually composed of technologies that are important both internally and externally.

Arpaci et al., (2012) asserts that the TOE framework for organizational adoption was developed by Tornatzky and Fleischer (1990) based on the Contingency Theory of Organizations. The TOE theory emphasizes that an effective organization should have a structure that is consistent with its environmental needs which influences the firm's adoption decision. The TOE framework as outlined by Oliveira and Martins (2010) is described as follows:

The technological context relates to technologies that are currently being used within the organization as well as new ones that are relevant to the organization.

$>$ The organizational context relates to the characteristics and resources of the organization that either constrain or promote the adoption process.

$>$ The environmental context relates to the environment in which the organization conducts its business which includes but not limited to competitors, industry and government which can motivate or create barriers to the adoption process.

Ven and Verelst (2011) contend that TOE framework is taxonomy for the classifying factors and, therefore, it does not describe all factors that influence the adoption process; and consequently, TOE framework in used in conjunction with other adoption models as it only encourages the researcher to take a broad view on the subject matter.

In addition, issues such as business infrastructure and procedures are often considered in the technical sense. On the other hand, scholars emphasize that "the organizational sense" talks about the company features and facilities like scale, centralization, and degree of formalization, structure of management, human resources, slacks, and staff relations. Finally, the environmental context defined by the scholars takes into consideration the industry aspect and structure, a company's competitiveness side, macroeconomic background and regulatory settings. 


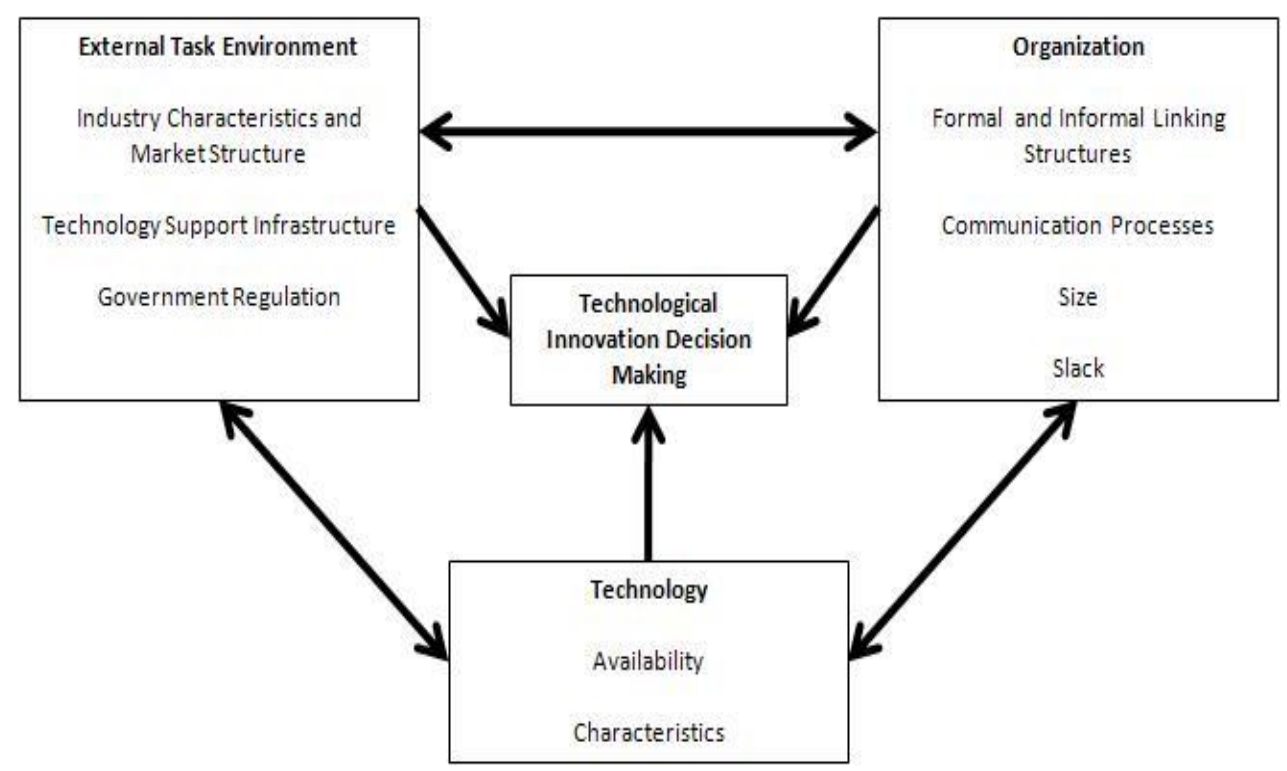

Fig 4:- Technology Organizational and Environmental Framework (Depietro, Wiarda et al., 1990)

\section{CONCEPTUAL RESEARCH FRAMEWORK}

Fundamentally, the Financial Service Provider Conceptual Research Framework (FSPCRF) offers a solid foundation for an analysis work undertaken to base the study on current and tested hypotheses that are considered suitable for study exploration. TOE Theory discussed in the previous section is essential to formulating the framework of conceptual research which supports this study by harvesting from certain aspects of these theory.

Bickman and Rog (2008) state that conceptual structure statements are used for offering a basic theory of what the research is about and why this phenomenon occurs. Conceptual model is described as a graphic or worded business model that "explains key factors, ideas or variables that need to be explored, and the implication of relationships between them, either graphically or in narrative form" (Miles et al., 1994). The hypotheses have been explored, and the conceptual research paradigm is the definitions taken mainly from the Technology, Organization, and Environmental Context (TOE).

Figure 5 Depicts Conceptual Research Framework for Digital Transformation for South African Financial Service Provider. Elements from the framework which suites this present study are described in table 2, theoretical framework is used as lenses, aid in the collecting of information.

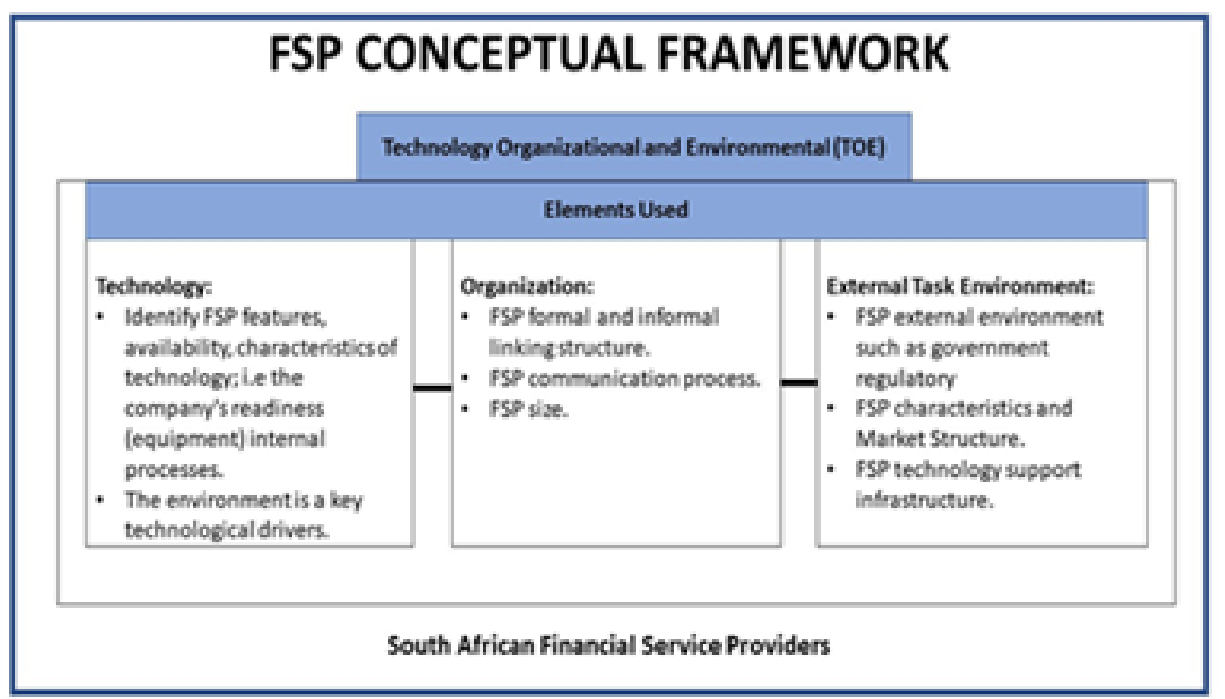

Fig 5:- Conceptual Research Framework for Digital Transformation for South African Financial Service Providers 
Table 2 on the next page contextualizes the CRF elements, these elements inform the study objectives and questions.

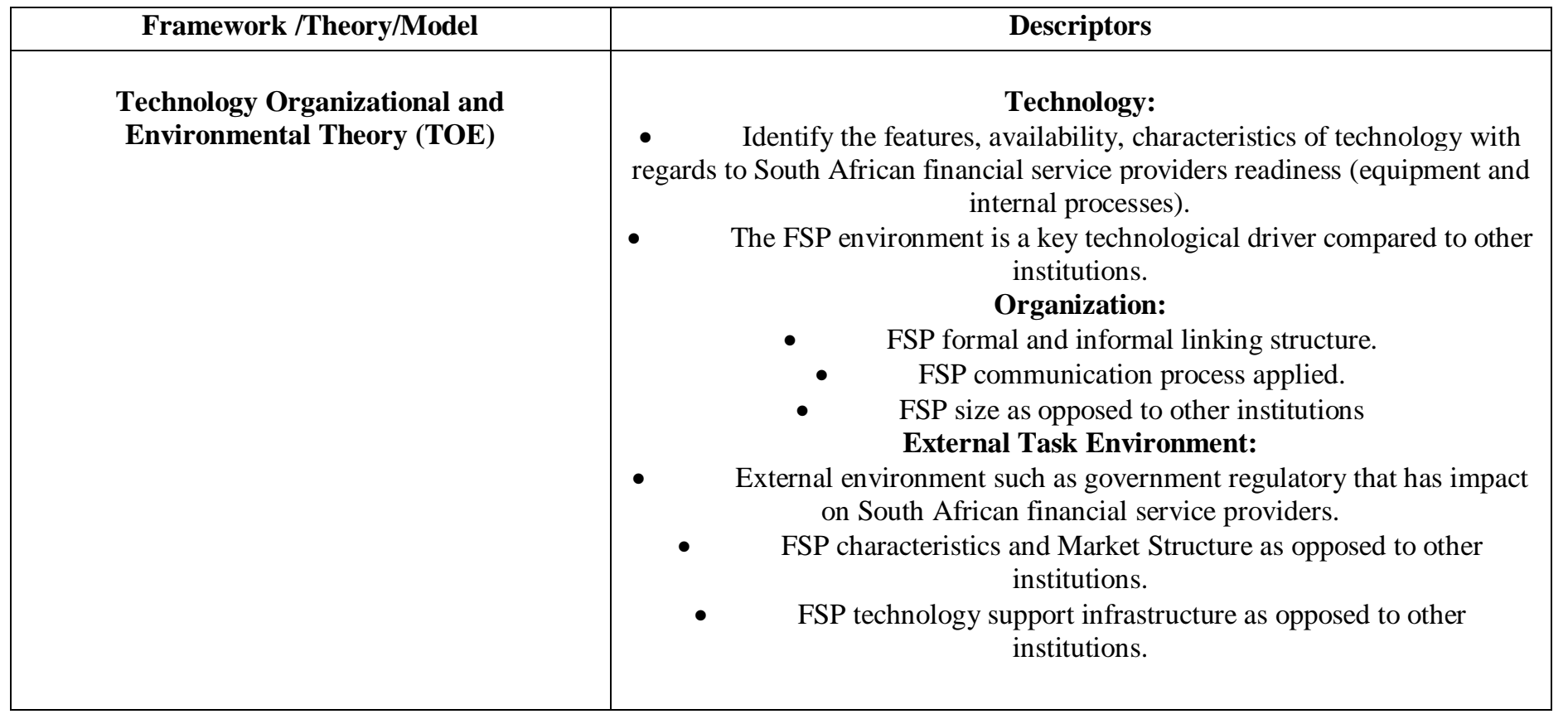

Table 2:- Elements of the CRF contextualized

The next section describes the methodology followed in this paper.

\section{METHODOLOGY}

\section{A. Interpretivist Paradigm}

According to Cohen and Manion (1994), "this applies to the nature of human experience" and the actuality of the environment is focused on social values (Mertens, 2014), research approaches are structured to explain the nature and experiences. According to Creswell and Creswell (2017), an interpretative or constructivist scientist uses the "participants' views of the situation being examined".

The study followed an interpretivist paradigm to study digital transformation in South African financial service providers. The reason interpretivist paradigm was followed is because the study sought to understand current status quo regarding how financial service providers in South Africa conduct digital business from their subjective experiences. This paradigm employs methodologies focused on attaching meanings from interviews and observations of study participants based on their subjective experiences. Additionally, this paradigm allowed for both deductive and inductive research approaches; that is, catering for both qualitative and quantitative research approaches.

\section{B. Inductive Reasoning}

This is defined as a concept that enables researchers to leverage what is already known to reduce the uncertainty about how the world is (Creswell and Creswell, 2017). This approach relies heavily on the definitions extracted from the collected data which are mainly qualitative. Since the analysis is based on current hypotheses, it is nevertheless inductive rather than deductive. The elements from the theory were used as lenses to what themes should be studied and analysed as opposed to testing and proving/disproving the theory constructs, deductively. With the inductive approach, the idea is to attach meanings to the elements as brought out during the collection of data, interviews and observations.

The study goal in qualitative research is exploratory and descriptive instead of explanatory (Ferreira et al., 1988). The descriptive aspect of qualitative research helps the author to describe the study participants' ' experiences, which either helps or contradicts the conceptual premises on which the analysis is focused (Wodak and Meyer, 2009) The descriptive aspect of qualitative research helps readers to understand what the experience means, what the issue is and how it works (ibid., 2009).

Qualitative research approach was appropriate for this study as the purpose was to explore and describe digital transformation process in its infancy stage with no known best practices for it, especially with regards to South African financial service providers. To this point, this study sought to formulate a framework that supports and informs digital transformation for South African financial service providers

\section{Research Strategy}

Yin (1991) defines case study research strategy as an "empirical investigation into a current phenomenon in its real-life sense, where the boundaries between phenomenon and sense are not clearly visible and where several sources of evidence are being used." Research case study approach provides a detailed version of what has occurred in this specific case, relationships, perspectives and methods. A detailed case study was taken into account in this analysis. 
Case study is defined as a comprehensive study of an individual, group of people, or an organization (in this paper, a financial service provider is the organization). This is case study of an organization with multiple business units, viewed as case units. Gustafsson (2017), classifies a person, organisation, society or any other entity which examines the depth of data as a systematic and intensive analysis. Case studies are the preferred strategy to examine a contemporary trend in its actual life and when working on a phenomenon that is in the early stages. This study applied a case study, a financial service provider, with multiple case units, 8 case units were studied.

For anonymity reason, Modiba Bank is the pseudonym used for the financial service provider studied. Modiba Bank is a Financial Service Provider doing business in South Africa with presence outside the African continent. Modiba Bank has a rich history in sub-Saharan Africa and Europe. The bank has an on-the-ground presence in more than 20 countries.

Modiba Bank is a diversified business that provides user solutions across the broad banking and financial products and services portfolio, namely:

Manufactured products.

Banking with hypothecs.

$>$ Products with cards.

$>$ Vehicle and Financial Assets (VAF).

$>$ Goods to lease.

$>$ Coverage of clients.

$>$ International Retailers.

$>$ Transactional goods and (TPS) utilities.

$>$ Hedging on investment.

$>$ Fixed term insurance plans and life insurance policies.

$>$ Modelling and financial forecasting.

$>$ Streamlined services to fiduciaries.

$>$ Customized financial products, asset management and advisory facilities.

$>$ Offshore banking facilities for consumers in Africa.

$>$ Services to finance, including regional wealth management.

$>$ The supermarket in South Africa.

$>$ Business development and Asset management.

\section{Research Design}

This section describes how the study was conducted. It defines the unit of analysis, population, sampling and the data collection methods used.

\section{Unit of Analysis}

Trochim (2006), states that deciding how you will analyse data collected for a study is to first define the analytical unit. Simply put, the analytical unit refers to the "which" or "what" and this may be a single student or a group to be analysed for the study proposed. The paper analyses financial service providers in South Africa. That is, the unit of analysis is the organization.

\section{$>$ FSP Population}

A population can be referred to as "aggregation of elements choosing a sample" (Mouton and Babbie, 2001). The population influences the sampling process (Black et al. 2000). Myers et al., (2002) suggest a survey of the people from whom it is taken to obtain information. This means that before using sampling methods, the population must be established and thoroughly researched.

The population in this study consists of financial service providers in South Africa, namely ABSA bank, Nedbank, Standard bank, African bank, Capitec, and the new Tyme bank, amongst others.

\section{$>$ Sampling Method}

Several forms of sampling are possible while conducting research, but researchers typically concentrate on relatively small (Lyell, 1998). Research subjects are usually selected for their ability to provide detailed explanations of interactions and to convey perceptions, thus providing rich knowledge that will challenge and improve the understanding of the researcher (Crabtree and Miller, 1992; Hutchinson and Wilson, 1991).

One large financial service provider out of the many forming the financial industry sector was purposefully selected. In terms of research, a data set known as sample refers to group of people, objects or items that can be taken for measurement from a larger population. Purposeful sampling was applied for this study, where the chosen financial service provider was chosen based on pre-selected requirements dependent on the research question, using a purposeful sampling was meant to focus on specific characteristics of a financial service provider.

\section{$>$ FSP Participants}

Semi-structured interview participants included individuals who have knowledge, experience and views about the business and its operations e.g. CIO, business owners, IT users and managers. The exact number of participants cannot be determined in qualitative research before the study is carried out. The researcher has specially selected participants who can contribute to the research subject and who are willing to share their experiences. The number of participants in qualitative research is guided by the degree to which the study question has been answered (Marshall, 1996; Øvretveit et al., 2002).

\section{> Data Collection}

The study collected primary data through semistructured interviews with individuals from the selected South African Financial Service Provider. Secondary data was collected through FSP documents. Additionally, Observation were also be applied as a technique to gather understanding of how FSP's conduct their business. This is the best method to get closer FSP's and understand their world fully prior to formulating a conceptual framework. The semi structured interviews were carried out at the organizations location or a place agreed with participants, the interviews was conducted with decision makers and 
individuals that are involved in the day to day running operational running of the business.

Denzin and Lincoln (2005) state that qualitative research stresses the importance of context in data analysis. The participants were able to decide on the venue for their interviews during the research process and particularly during the data collection phase. It resulted in each participant's being interviewed in a position that was convenient to them and selected by them. South Africa is unique with various languages, but English was the language used to conduct interviews and interviews were recorded then transcribed. Each interview lasted for about 30-45mins.

Although semi-structured interviews were part of this study, the findings in this paper focused on data collected from FSP documents such as report, policies and manuals.

\section{$>$ Data Analysis:}

Mouton and Marais (1991) describe an analysis of the data as the mechanism by which a phenomenon is split into its components to better understand it. Data analysis was intended to describe or illustrate data evaluation.

Through this research, versions of digital transformation understanding, knowledge were identified from the perspective of the participants rather than an absolute answer to the problem. Inductive studies allow for subjective approach when interreacting with participants. Ibid et al., (2002) claim that content analysis and thematic analysis have become South African content researchers' favourite approach. Although, the ibid., (2002) do not explain the popularity of content analysis and thematic methodologies in South Africa, it can be assumed that the support of postmodern research for multifaceted perspectives and multiple constructed identity fits comfortably with the diverse society of South Africa.

\section{- Thematic Analysis:}

In this study thematic analysis was deemed appropriate based on what is already discussed. The topic analysis can be defined as a way of defining, analysing and interviewing data. The data collection and analysis (Braun and Clarke, 2006) was explained in depth. Inductively 'bottom up' or inductively, 'top down' can be described as the themes (Boyatis, 1998). Theoretical thematic analysis helps the researcher to interpret the research data based on research questions through which the theoretical lens affects these research questions. Therefore, for this study theoretical thematic analysis was appropriate and used for analysis of the data collected through interviews. The thematic analysis is the information collection tool for the development of thematic significance and output.

\section{- Content Analysis:}

Data can also be analysed using content analysis. The cycle requires documentation of emerging topics (Hsieh and Shannon, 2005). The content analysis, which uses a document review methodology, was in the present study, followed to make sense of the financial service provider's documents and manuals. According to Bernard (2017), in order to answer a question or to solve a problem, a content review is carefully considered for collecting and understanding information or facts. Of great importance is the assessment of the credibility, trust and order of events. Content analysis was used to categorize objects that are fairly reliable and augmented data analysed through thematic analysis. The most important thing is orderly, logical statements based on the model and the analysis, collection and interpretation of the material to complete the results (Schreier, 2012).

\section{DISCUSSION OF FINDINGS}

\section{A. Technological, organizational and environmental Findings from Analysis of Financial Service Provider Documents}

Technological, organizational and environmental finding from FSP documents are articulated below as per below subsections with regards to the three contexts of the Technological, organizational and environmental theory per sub section below:

\section{* FINDINGS FROM ANALYSIS OF FINANCIAL SERVICE PROVIDER DOCUMENTS $\square \square \square$ Technological Context \\ $>$ Digitisation}

FSP ensures that people have access to convenient information relating to digital solutions ranging from selfservice technologies to interconnected global networks to solutions to people management. Group-wide efforts to implement digital technologies to improve organizational efficiency and access to networking and communication processes are under way.

\section{$>$ Banking platforms}

Technology has upgraded key banking channels with the latest digital technology. Investments in customercentered technologies are driving rapidly evolving consumer preferences and behaviours. Africa has increased its financial access, especially in rural areas, through advances in digital and mobile technology.

\section{$>$ Cloud Computing}

The cloud computing industry is expected to grow in 2020 to USD 191 billion. As the associated threats and the increased deployment of complex algorithms and cognitive tools such as chatbots are largely unknown, a balanced digitalization strategy is required to handle all negative consumer impacts, to minimize unintended systems interference and to improve data protection.

\section{Artificial intelligence}

Despite scarcer resources and implementing digital approaches the need for successful management of artificial intelligence (AI) would increase. In order to meet the cultural change required for AI, improvements would be needed in both people with the requisite skills and new ways of working to enable more creative thought, problem solving, flexibility and innovation 


\section{Design thinking}

The use of design concepts in daily experiences is design thinking. It includes problem detection, analysis of potential solutions and concepts, and prototyping of concepts. Design thinking helps to enhance the centralization and reaction of consumers, personalizing goods and services for each customer.

\section{$>$ Data privacy and security}

New rules that place important obligations for financial institutions to protect and use data responsibly and to respect the privacy rights of customers address global concerns relating to data, privacy and consumer rights.

\section{$>$ Digital currencies and blockchain technology}

Digital and blockchain currencies technology allow anonymous transactions to support consumer privacy and data security. The emergence of quantum technology, however, may undermine the digital economy's stability.

\section{Technical Skills development}

Annual employee survey responses indicate that while most workers are happy with their job opportunities and skill growth, opportunities for advancement are accessible.

\section{Cybersecurity}

- IT system stability, protection and speed.

- Operative and reputational risk to third parties, colleagues and suppliers.

- Fraud card continuing concern.

\section{$>$ Technology adoption}

Technology adoption ensures that FSP accepts, integrates and uses emerging technologies for society. The process follows multiple stages, which usually include people in the technical units.

\section{Enterprise technology}

Business technology FSP is a vital enabler of integrated approaches to financial services. We have developed organization assets that can be leveraged across business units and functions, with modernized IT systems allowing multidisciplinary operating teams to build creative, continually evolving digital solutions.

\section{System Integration}

The FSP method of integrating the subsystems in a single system (an aggregation of subsystems that collaborate to guarantee that the system provides unified functionality) and ensuring that subsystems act as a system and IT systems that link different computer systems and software applications physically or functionally. The benefits of switching from the old to the new platforms are numerous and lie primarily in the modular design of the integration process.

\section{B. Organizational Context}

$>$ FSP Business activities

- Lend our clients' money.

- Company and other funder's sources of financing.

- Provide customer services and knowledge-based transactional bank facilities

- Company access to market and risk mitigation products.

- Other sources of income related to core companies and strategic investments.

\section{Value creation model}

In the dynamic environment of conflicting demands, complex competition forces and regulatory pressures, our business models will adapt to commercial and social realities. In doing what we do and how we do, we are committed to managing our resources and relationships professionally to produce the best outcomes for our customers, employees, shareholders, and others.

\section{Strategy}

The FSP approach is built to take advantage of Africa's opportunities. Our three key focus areas ensure that we provide our clients with the solutions they need as effectively as possible and concentrate our attention on our strategic value drivers and evaluate progress towards delivering value.

\section{$>$ Partnership}

FSP strategic alliance with ICBC allows us to fulfill the need of Africa-China corridor customers. In each of the markets in Africa regions, the FSP is growing potential for Chinese-language relations managers.

\section{- Change Management}

FSP Change Management is the use of processes and resources to handle the transition side from a current state to a new future such that the intended outcomes of the transition are achieved.

\section{$>$ People}

FSP People are the drivers of organizational goals and thus, leadership and employees are essential to maximize organizational results efficiently and secure.

\section{$>$ Role of leadership}

Effective management is seen by the FSP as uniting goal and performance by incorporating an ethical and riskconscious culture that acknowledges that the confidence of the stakeholders in which we perform and succeed.

\section{Business activities and outputs}

Our operating divisions and organizational departments operate together to meet our customers' expectations as an essential financial sector agency delivering a wide range of products and services. 


\section{Global disruption}

The complexity and ever-advancing technology of the Fourth Industrial Revolution have rendered it difficult to detect new developments effectively. The World Economic Forum tracks patterns that form potential landscapes that are vital to global, political, manufacturing, scientific, environmental, social and finance operations. Such developments could contribute to innovations which will affect the potential working and capability demands of all facets of society, including social and monetary structures.

\section{$>$ Regulations}

The primary drivers of global regulatory innovations remain financial regulation, technical advancement and conduct while regulators need rigorous data security and privacy monitoring.

\section{Financial inclusion}

In sub-Saharan Africa, $43 \%$ of adults (ages 15 or older) already have a bank account, compared with $34 \%$ in 2014. $33 \%$ have a financial institution wallet, while $21 \%$ have a mobile money wallet, up from $12 \%$ in 2014. More than half the adult population in Africa is still removed from the formal financial structure though a remarkable change is made. The Fin-dex study states that 'financial innovations' have the most compelling ability to extend exposure and usage accounts in Sub-Saharan Africa' where 34 percent of adults have made digital payments or received them in the past year.

\section{$>$ Infrastructure development}

Investments of infrastructure from USD 130 billion to USD 170 billion per year are expected to be needed through Africa in the African Development Bank. The continent will make best use of current infrastructure in order to sustain development, whilst building new infrastructure. Investment in modern transport networks would be important, for instance, in rapid growth of transport and the growth of autonomous vehicles.

\section{$>$ Client focus}

- Efficient client interactions built on trust, solid corporate relationships, like our ten-year ICBC relationship, reward our consumers through tailored consumer journeys.

- Workers trained to offer excellent consumer services.

- Customer-centered, automated operating processes.

- Division suit and network ATM. Suit for function.

- Primary (direct) services and funding (indirect) operations.

\section{$>$ Employee engagement}

FSP has a philosophy of caring, development, learning and technological advances:

- Solid corporate and leadership structures

- Engaged and competent workers

- Great partnerships with employee members

- Quality and reputation driver incentive systems

- High-performance ethical framework
- Innovation in preparation that encourages customercentered ways of operating

\section{$>$ Financial Outcome}

- Efficient investment plan, how do we do business contributes to higher shareholder returns.

- Competitive exposure to finance and a stable and flexible system of resources.

- Workers value the interest they receive competitively.

- Strong financial group reputation.

$>$ Employee development and training

- Development and retention of existing expertise in our operating countries;

- Programme for growth.

\section{Impact}

The FSP delivers shared value:

- Promoting socio-economic prosperity and competitive economies

- Environmental risk reduction research for customers, through the usage of Equator Theory

- Responsible business and consumer expansion

- Respected and ethical brand.

\section{> FSP Performance indicators}

- Net promoter score (NPS) indicates how much FSP is suggested by a retail consumer to work well. It is determined by eliminating promoter detractors. When any consumer is a detractor, the benefit will be of -100 or +100 if each consumer is a promoter. Any ranking above 0 indicates that there are more supporters than detractors.

- The Consumer Satisfaction Index (CSI) is the metric of which CIB's operation delivers value to both our corporate and investment customers. This is measured with weighted ratings from reactions to the efficacy of consumer service services across various measurements.

- Employee turnover: tests the proportion of workers quitting our workplace.

- Employment equity: measures the representation of black people in management levels in South Africa.

\section{Environmental Context}

\section{$>$ Describe competition within the industry}

Traditional banks are constantly faced by the market's competitiveness, especially with modern, cheaper, more convenient, more open and faster customized digital service providers. Investment in consumer-centered technologies fuels quickly evolving market preferences and attitudes. Sources of potential entrants include the latest arrival in South Africa of Tyme Bank, with the Discovery Bank and Bank Zero in the immediate future.

\section{Politics}

Renewed confidence has been affected by divisions, political instability and weak governance of state-owned enterprises that threaten institutional capacities. The rising instability in the world threatens foreign collaboration and 
commercial ties. Sub-Saharan Africa tends to battle for precarious democratic order, though accelerated institutional changes have strengthened economic prosperity.

\section{Economics}

Current trends of developed economies are likely to slow down owing in part to US-China friction over trade and under-optimal Brexit talks, declining stock sector confidence, and worries about Chinese growth outlook. The international economy conditions are sub-standard. All in all, African economies have been resilient and build traction by enhanced economic and structural diversification in order to connect jobs and minimize poverty. In 2019, the IMF7 expects a $3.5 \%$ growth in the global economy. The GDP growth is expected to increase by $3.5 \%$ in 2019 , and by $3.6 \%$ in 2020 in sub-Saharan Africa.

\section{$>$ Rapid urbanization and youthful population}

Africans are projected to increase their population by 2050 , with an average age of 20 and an additional 1.5 billion Africans of working age2. As a consequence, policymakers are experiencing growing competition for employment, health care and social services funding. There are incentives to improve financial connectivity in urban centers by way of cheap digital transfers and housing and small business initiatives. New expertise to apply to the new financial services market would be required to exploit these and other opportunities.

\section{$>$ Risk and Conduct}

The FSP has a culture of caring, growing, learning and innovation:

- Constructive ties and continuing communication with government and regulators.

- Embedding a philosophy of danger consciousness, enforcement and ethics.

- Solid management monitoring mechanisms and structure for risk and

\section{$>$ Risks and opportunities}

The FSP is pursuing a systematic plan to recognize the key challenges and potential threats the organization and countries in which we operate. This focusses our attention and prioritizes our reactions to the challenges, prospects and threats that may impact our strategic capacity.

\section{$>$ Governance}

The activities are built into FSP governance and risk structures, to allow better transparency, successful risk control, consistent monitoring of the results, more open and productive governance.

\section{Operational Culture}

The FSP offers enhanced value to our customers and has launched a series of strategic interventions and business paradigm convergence strategies to facilitate critical organizational changes to ensuring that we have the best resources to management skills in place. They are finding innovative approaches to ensure that agile multidisciplinary teams can adapt rapidly to growing consumer and market demands.

\section{$>$ Compliance}

- Key business financial, legal and administrative threats.

- Develop ties with the governing bodies in order to ensure compliance.

- Rising risks to physical safety / incidents in African regions related to non-compliance

\section{$>$ Enterprise risk management (ERM)}

The risk and capital management strategy is described in the FSP governance system. The system comprises organizational principles, process structures and rules and is enforced through approved and assigned authority by board and policy committees. We look at challenges that we pose, and continuously analyze all current and new hazards in our organizational environment, as a whole and for the future.

\section{Technology Risk}

This form of risk is linked within the FSP to the use, possession, service, participation, impact and acceptance of technology. It consists of incidents and circumstances related to technology that may theoretically affect the company, including improvements in technology, upgrades or alterations. The Group's successful use of innovations in achieving business goals and becoming competitive is a key factor within technology risk.

\section{FSP TECHNOLOGICAL, ORGANIZATIONAL AND ENVIRONMENTAL DIGITAL TRANSFORMATION FRAMEWORK}

This section outlines the conceptual FSP Technological, organizational and environmental framework in parts, namely Organizational, Technology and Organizational culture which cuts across all pillars, and they are articulated as per below subsections, then the framework placed together:

\section{A. Interpretation of elements of the FSP Technological, organizational and environmental digital Transformation Framework}

Figure 6 Below, is a bird view of the contextual technological, organizational and environmental Digital Transformation framework for South African Financial Service Providers: 


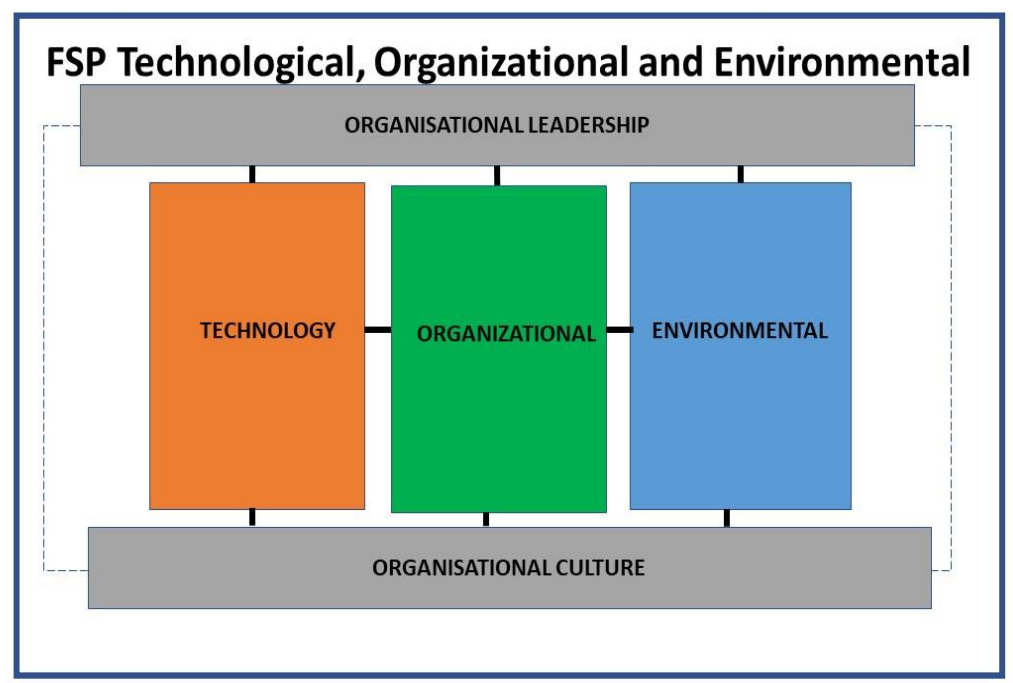

Fig 6:- Technological, organizational and environmental Digital Transformation framework for South African Financial Service Providers

The below table 3 outlines the elements that characterizes the framework:

\begin{tabular}{|c|c|}
\hline Critical Factors & Elements \\
\hline Organisation Leadership & $\begin{array}{c}\text { Role of leadership } \\
\text { Client focus } \\
\text { Employee engagement } \\
\text { Employee development and training/Coaching }\end{array}$ \\
\hline Organisational Culture & $\begin{array}{c}\text { Micromanaging } \\
\text { Changes from leadership perspective } \\
\text { Changing mind-set } \\
\text { Collaboration opportunity } \\
\text { Alignment to objectives Autonomy } \\
\text { Information sharing } \\
\text { Visibility of vision }\end{array}$ \\
\hline Technology Context & $\begin{array}{c}\text { Digitisation } \\
\text { Banking platforms } \\
\text { Cloud Computing } \\
\text { Artificial intelligence } \\
\text { Design thinking } \\
\text { Data privacy and security } \\
\text { Digital currencies and blockchain technology } \\
\text { Technical Skills development } \\
\text { Cybersecurity } \\
\text { Technology adoption } \\
\text { Enterprise technology } \\
\text { System Integration }\end{array}$ \\
\hline Organisational Context & $\begin{array}{c}\text { FSP Business activities } \\
\text { Value creation model } \\
\text { Strategy } \\
\text { Partnership } \\
\text { Change Management } \\
\text { People } \\
\text { Role of leadership } \\
\text { Business activities and outputs } \\
\text { Global disruption } \\
\text { Regulations } \\
\text { Financial inclusion } \\
\text { Infrastructure development }\end{array}$ \\
\hline
\end{tabular}


ISSN No:-2456-2165

\begin{tabular}{|c|c|}
\hline & $\begin{array}{c}\text { Customer priority } \\
\text { Staff participation } \\
\text { Financial impact } \\
\text { Development and training of employees } \\
\text { Impact } \\
\text { FSP Performance indicators } \\
\end{array}$ \\
\hline Environmental Context & $\begin{array}{c}\text { Competition within the industry } \\
\text { Politics } \\
\text { Economics } \\
\text { Rapid urbanization and youthful population } \\
\text { Risk and Conduct } \\
\text { Risks and opportunities } \\
\text { Governance } \\
\text { Operational Culture } \\
\text { Compliance } \\
\text { Enterprise risk management (ERM) } \\
\text { Technology Risk }\end{array}$ \\
\hline
\end{tabular}

Table 3:- Elements of the CRF contextualized

\section{CONCLUSION}

Study findings suggest that digital transformation within FSP in South Africa is either enabled or inhibited by existing technological, organizational and environmental (TOE). The paper argues and concludes that technological, organizational and environmental (TOE) ought to manifest cognizant of the FSP's contexts. The technological, organizational and environmental digital transformation framework conceptualised unpacks the theoretical, practical, and contextual contributions of this paper.

\section{REFERENCES}

[1]. ANDERSON, C, FINDLING., S.N.G.S., STROHLEIN., M, CARTER., P, HAND., L, PARKER., R. (2015). IDC FutureScape: worldwide digital transformation $2016 . \quad$ IDC. https://www.odc.com/getdoc.jsp?containerId=259616. Accessed 4 November 2019.

[2]. ARPACI, I., YARDIMCI, Y. C., OZKAN, S. AND TURETKEN, O. (2012). Organizational adoption of information technologies: A literature review. International Journal of ebusiness and egovernment Studies, 4, 37-50.

[3]. BERITELLI, P., BIEGER, T., LAESSER, C. (2007). Destination Governance: Using Corporate [2] Governance Theories as a Foundation for Effective Destination Management. Journal of Travel Research, 46(1), pp.96-107.

[4]. BERMAN, S.J. AND BELL, R. (2011). Digital transformation: Creating new business models where digital meets physical. IBM Institute for Business Value, pp.1-17.

[5]. BERNARD, H.R. (2017). Research methods in anthropology: Qualitative and quantitative approaches. Rowman \& Littlefield.

[6]. BICKMAN, L. AND ROG, D. J. (2008). The SAGE handbook of applied social research methods, Sage publications.
[7]. Black, D., Gates, G., Sanders, S. and Taylor, L. (2000). Demographics of the gay and lesbian population in the United States: Evidence from available systematic data sources. Demography, 37(2), pp.139-154.

[8]. BLOOMBERG, J. (2018). Digitization, digitalization, and digital transformation: confuse them at your peril. Retrieved from https://www.forbes.com/sites/jasonbloomberg/2018/0 4/29/digitization-digitalization-and-digitaltransformation-confusethem-at-yourperil/\#2dd1ce842f2c.

[9]. BONNET, D. AND NANDAN, P. (2011). Transform to the power of digital: Digital transformation as a driver of corporate performance. report, Capgemini Consulting.

[10]. BOYATZIS, R.E. (1998). Transforming qualitative information: Thematic analysis and code development. Sage.

[11]. BRAUN, V. AND CLARKE, V. (2006). Using thematic analysis in psychology. Qualitative research in psychology, 3(2), pp.77-101.

[12]. CENSUS. (2011). Census in brief (PDF). Pretoria: Statistics South Africa. 2012. pp. 23-25. ISBN 9780621413885.

[13]. COHEN, L. AND MANION, L. (1994). Research methods in education 4th edition Routledge, London.

[14]. CRABTREE, B.F. AND MILLER, W.L. (1992). Doing qualitative research. In Annual North American Primary Care Research Group Meeting, 19th, May 1989, Quebec, PQ, Canada. Sage Publications, Inc.

[15]. CRESWELL, J. W. AND CRESWELL, JD. (2017). Research design: Qualitative, quantitative, and mixed methods approaches, Sage publications.

[16]. DAUGHERTY, P., BANERJEE, P. AND BILTZ, M.J. (2015). Digital business era: stretch your boundaries. Technology Vision 2015.

[17]. DELOITTE. (2018). Digital enablement turning your transformation into a successful journey. Retrieved from 
https://www2.deloitte.com/content/dam/Deloitte/ie/Do cuments/Technology/IE_C_HC_campaign.pdf

[18]. DENZIN, N.K. AND LINCOLN, Y.S. (Eds.). (2005). Handbook of qualitative research (3rd ed.). London: Sage.

[19]. DEPIETRO, R., WIARDA, E. AND FLEISCHER, M. (1990). The context for change: Organization, technology and environment. The processes of technological innovation, 199(0), pp.151-175.

[20]. DESMET, D., DUNCAN, E., SCANLAN, J. AND SINGER, M. (2015). Six building blocks for creating a high performing digital enterprise. McKinsey \& Company.

[21]. DREISCHMEIER, R., CLOSE, K. AND TRICHET, P. (2015). The digital imperative. BCG Perspectives.

[22]. EBERT, C. AND DUARTE, C. H. C. (2016). Requirements engineering for the digital transformation: Industry panel. 2016 IEEE 24th International Requirements Engineering Conference (RE), IEEE.

[23]. ERNST AND YOUNG. (2011). The digitisation of everything.

http://www.ey.com/Publication/vwLUAssets/The_digi tisation_of_everything_How_organisations_must_ad apt_to_changing_consumer_behaviour/\$FILE/EY_Di gitisation_of_everything.pdf. Accessed: 11.08.15

[24]. EUROPEAN COMMISSION. (2019). Digital transformation. Retrieved fromhttps://ec.europa.eu/growth/industry/policy/digita ltransformation_en.

[25]. FERREIRA, M., MOUTON, J., PUTH, G., SCHURINK, E. AND SCHURINK, W.J. (1988). Introduction to qualitative research methods. HSRC.

[26]. FRIEDRICH, R., LE MERLE, M., PETERSON, M. AND KOSTER, A. (2011). The next wave of digitization: setting your direction. Building Your Capabilities, Booz \& Company, Dusseldorf.

[27]. GARTNER. (2020). Digitalization. Retrieved 26 January 2020, from https://www.gartner.com/en/informationtechnology/glossary/digitalization.

[28]. GIMPEL, H. AND RÖGLINGER, M. (2015). Digital transformation: changes and chances-insights based on an empirical study.

[29]. GUSTAFSSON, J. (2017). Single case studies vs. multiple case studies: A comparative study.

[30]. HIRT, M. AND WILLMOTT, P. (2014). Strategic principles for competing in the digital age. McKinsey Quarterly, 5(1), pp.1-13.

[31]. HSIEH, H.F. and SHANNON, S.E. (2005). Three approaches to qualitative content analysis. Qualitative health research, 15(9), pp.1277-1288.

[32]. HUTCHINSON, S.A. AND WILSON, H.S. (1991). Triangulation of qualitative methods, Heideggerian hermeneutics and grounded theory. Qualitative Health Research, 1(2), 263-276.

[33]. ISMAIL, M. H., KHATER, M., AND ZAKI, M. (2017). Digital business transformation and strategy: What do we know so far? Retrieved from https://cambridgeservicealliance.eng.cam.ac.uk/resour
ces/Downloads/Monthly\%20Papers/2017NovPaper_ Mariam.pdf.

[34]. LOPEZ, J. (2014). Digital business is everyone's business. Forbes.

[35]. LYELL, C. V. (1998). Perpetrators of child sexual abuse: Social constructionist and traditional empirical approaches, University of Johannesburg.

[36]. MARKOVITCH, S. AND WILLMOTT, P. (2014). Accelerating the digitization of business processes. McKinsey-Corporate Finance Business Practice, pp.14.

[37]. MARSHALL, C. (1996). Designing qualitative research. London: Sage.

[38]. MATT, C., HESS, T. AND BENLIAN, A. (2015). Digital transformation strategies. Business and Information Systems Engineering, 57(5), pp.339-343.

[39]. MERTENS, D. M. (2014). Research and evaluation in education and psychology: Integrating diversity with quantitative, qualitative, and mixed methods, Sage publications.

[40]. MILES, M.B., HUBERMAN, A.M., HUBERMAN, M.A. and HUBERMAN, M. (1994). Qualitative data analysis: An expanded sourcebook. Sage.

[41]. MORGAN, J. (2014). A simple explanation of the internet of things. Retrieved November 20, 2015.

[42]. MOUTON, C.J. AND MARAIS, H.C. (1991). Basic concepts in the methodology of the social sciences. Pretoria: Human Science Research Council.

[43]. MOUTON, J. AND BABBIE, E. (2001). The practice of social research. Cape Town: Wadsworth Publishing Company, pp.871-890.

[44]. Myers, M.D. and Avison, D. eds. (2002). Qualitative research in information systems: a reader. Sage.

[45]. NEGROPONTE, N. (1995). Being Digital. The Alfred A. Knorpf. New York.

[46]. NYLÉN, D. AND HOLMSTRÖM, J. J. B. H. (2015). Digital innovation strategy: A framework for diagnosing and improving digital product and service innovation.58 (1): 57-67.

[47]. OECD. (2018). Going digital in a multilateral world. Retrieved from https://www.oecd.org/going-digital/CMIN-2018-6-EN.pdf.

[48]. OLIVEIRA, T. AND MARTINS, M.F. (2010). Understanding e-business adoption across industries in European countries. Industrial Management and Data Systems 110(9): 1337-1354.

[49]. OPITZ, M, SCHREIBER, B, PFIRSCHING, V, GONZALEZ, A, GNIRS, T, MOHR, G, PEINTNER, S, KRAUSE, O. (2015). Digital transformation- how to become a digital leader. Study 2015-resukts. Arthur D. Little. http://www.adlittle.fr/uploads/tx_extthoughtleadership /ADL_HowtoBecomeDiditalLeader.pdf. Accessed 22 Nov 2019.

[50]. OSTERWALDER, A. AND PIGNEUR, Y. (2010). Business model generation: a handbook for visionaries, game changers, and challengers. John Wiley \& Sons 
[51]. ØVRETVEIT, J., BATE, P., CLEARY, P., CRETIN, S., GUSTAFSON, D., MCINNES, K., MCLEOD, H., MOLFENTER, T., PLSEK, P., ROBERT, G. AND SHORTELL, S. (2002). Quality collaborative: lessons from research. Qual Saf Health Care, 11(4), pp.345351.

[52]. PARKER, C. AND THOMSON, S. (2016). Recap of Davos 2016. In World Economic Forum. http://www.weforum.org/agenda/2016/01/a-recap-ofdavos-2016. Accessed (Vol. 22).

[53]. RACONTEUR. (2016b). Cyber Security. Raconteur.net, March 2016. http://raconteur.net/cyber-security-2016. Accessed 22 October 2019.

[54]. SCHREIER, M. (2012). Qualitative Content Analysis in practice. Scientific study of literature. 3:1 (165168).

[55]. SCHWAB, K. (2016). The Fourth Industrial Revolution (Geneva: World Economic Forum). ekonomika preduzeća ekonomika $\mathrm{p}$ ekonomika $\mathrm{pr}$ ekonomika pre ekonomika pred ekonomika preduz ekonomika preduze konomika preduzeća nomika preduzeća omika preduzeća mika preduzeća ika preduzeća a preduzeća.

[56]. SCHWERTNER, K. (2017). Digital transformation of business. Trakia Journal of Sciences, 15(1), 388-393. https://doi.org/10.15547/tjs.2017.s.01.065.

[57]. TORNATZKY, L. AND FLEISCHER, M. (1990). The process of technology innovation. Lexington, MA: Lexington Books, 165.

[58]. TROCHIM, W. M. (2006). The research methods knowledge base, 2nd.Edition. Internet WWW page, at URL: http://www. Social research methods. net/kb/(version current as of October 20, 2006).

[59]. VEN, K. AND VERELST, J. (2011). An empirical investigation into the assimilation of open source server software. Communications of the association for information systems 28(1): 9 .

[60]. WESTERMAN, G., CALMÉJANE, C., BONNET, D., FERRARIS, P. AND MCAFEE, A. 2011). Digital Transformation: A roadmap for billion-dollar organizations. MIT Center for Digital Business and Capgemini Consulting, 1, 1-68.

[61]. WODAK, R. and M. MEYER (2009). Critical discourse analysis: History, agenda, theory and methodology. Methods of critical discourse analysis 2: 1-33.

[62]. YIN, R. (1991). Case study research: design and methods. Newbury Park, Rev. ed, Sage Publications. 